\title{
Program Design and Long-Run Costs of a National Catastrophic Drug Insurance Plan
}

\section{Conception et coûts à long terme d'un programme national d'assurance médicaments pour les cas de prix exorbitants}

\author{
$\sqrt{5}$ \\ by HAI ZHONG \\ School of Public Finance and Public Policy \\ Central University of Finance and Economics \\ Beijing, China
}

\begin{abstract}
There are strong arguments that national catastrophic drug insurance should be established in Canada with assistance from the federal government. The author of this paper projects the long-run program costs for two proposals for such a program: that of the Kirby Committee and that of the Romanow Commission. He concludes that both the annual program costs to the federal government and the share of the federal government on total prescription drug expenditures in Canada would increase dramatically under either program. Although the Kirby-style program requires less initial expenditure by the federal government than does the Romanow-style program, because of their different designs, over time the Kirby-style program would become more expensive. Moreover, the Kirby-style program would be more sensitive to the
\end{abstract}


growth rate of prescription drug expenditure. The choices relating to the program threshold and federal cost-sharing rate have far-reaching influences on the long-run costs to the federal government.

\section{Résumé}

Il y a de nombreux arguments en faveur de l'établissement, au Canada, d'un régime national d'assurance médicaments pour faire face aux situations où les coûts des médicaments d'ordonnance sont exorbitants; régime qui se ferait avec la participation du gouvernement fédéral. L'auteur de l'article projette les coûts à long terme d'un tel programme en fonction de deux propositions en ce sens : celle du rapport Kirby et celle du rapport Romanow. L'auteur conclut que les coûts annuels du programme pour le gouvernement fédéral et que la part du gouvernement au total des dépenses pour les médicaments d'ordonnance au Canada augmenteraient considérablement dans le cas des deux programmes proposés. Bien que le programme de Kirby nécessite moins de dépenses initiales de la part du gouvernement fédéral que le programme de Romanow, en raison des différences de conception, à la longue le programme de Kirby serait plus coûteux. De plus, le programme de Kirby serait plus sensible à la croissance des taux de dépense pour les médicaments d'ordonnance. Les choix quant au seuil-limite et au taux de partage des frais du gouvernement fédéral ont une profonde influence sur les dépenses à long terme pour le gouvernement.

\section{$\boldsymbol{C}_{\text {he Canada Health Act does not apply to prescription drugs }}$ used outside the hospital setting. Coverage for prescription drugs in Canada is offered through a mixture of public and private insurance plans, both of} which vary significantly in terms of eligibility, co-insurance rate, deductibles and drug formulary. Many Canadians have no coverage at all. According to estimates by the Fraser Group and Tristat Resources (2002), 2\% of Canadians $(600,000)$ do not have any sort of prescription drug coverage. Nine per cent of Canadians have drug coverage plans without caps on out-of-pocket costs. In total, $11 \%$ of Canadians are estimated to be at substantial financial risk from high prescription drug expenses paid out of their own pockets.

Prescription drugs have become an increasingly important component of healthcare services. Between 1975 and 2004, per capita prescription drug expenditure rose from $\$ 119$ to $\$ 562$ (in 2004 constant dollars), and spending on prescribed drugs as a proportion of total health expenditure has increased from $6.3 \%$ to $13.8 \%$ (CIHI 2005a,b). Prescription drug spending has increased at a more rapid rate than any other component of health expenditure. 
For many individuals and families in Canada, financial hardship resulting from high prescription drug expenses and lack of adequate insurance protection is an increasing risk. In contrast, many OECD countries provide publicly funded coverage for prescription drugs as well as for hospital and physician services (Kirby 2002). Therefore, in both the report by the Standing Senate Committee on Social Affairs, Science and Technology (Kirby Committee) and the report by the Commission on the Future of Health Care in Canada (Romanow Commission), there are strong arguments that the principles of the Canada Health Act should be extended to prescription drugs used outside the hospital setting (Kirby 2002; Romanow 2002). Latterly, at the 2004, 2005 and 2006 Council of the Federation meetings, the premiers of all Canadian provinces and territories consistently called on the federal government to take steps to ensure that all Canadians have access to the drugs they need when they need them. At the September 2004 meeting of First Ministers, the federal government agreed that health ministers be directed to establish a Ministerial Task Force (MTF) to develop and implement a national pharmaceutical strategy. In September 2006, the MTF released the National Pharmaceuticals Strategy Progress Report, which provides a snapshot of progress to date and MTF recommendations on the development and implementation of the multi-year National Pharmaceuticals Strategy (NPS).

At present, the national catastrophic drug plan is still being developed. Available options include proposals in the Kirby Report, the Romanow Report and the National Pharmaceuticals Strategy Progress Report (Kirby 2002; Romanow 2002; Health Canada 2006). Table 1 provides a summary of the basic features of the three proposals.

All three proposed programs share some common design features. Although they make different choices about the level of the catastrophic threshold and sharing rate of involved payers, all three assume that in the future the public sector will be willing to undertake a certain responsibility for catastrophic prescription drug expenditures.

While all three proposed programs have a common ultimate goal - protecting Canadians from catastrophic drug expenditures - they offer different approaches to reach it. The NPS and Kirby programs directly target individuals in Canada. The Romanow program recommends establishing a national catastrophic drug transfer. This new transfer would assign funds to provincial/territorial drug plans to help them cover high prescription drug costs. In return for this increased federal transfer, provinces and territories would be expected to expand their coverage and to reduce disparities across the country.

While both the Kirby and Romanow proposals clearly specify the financial responsibility of the key players in the proposed programs, there is no role for private drug plans in the Romanow program. The National Pharmaceuticals Strategy Progress Report (Health Canada 2006) emphasizes that one of the focuses of the NPS in the next stage is the role of engaged stakeholders.

At the stage of designing the structure for a national program, cost is an impor- 
tant concern. In all three proposals, the annual program cost for the first year has been estimated. In the Kirby Report, the estimated initial annual cost of the proposed program to the federal government at 2000 was $\$ 500$ million. In the Romanow Report, the estimated initial annual cost of the proposed program to the federal government at $2000 / 01$ was $\$ 749.1$ million to $\$ 1.01$ billion. To demonstrate the impact of maintaining private insurance coverage, the NPS cost estimates for each threshold option have been provided both with and without a private insurance role in paying catastrophic drug costs. The annual cost for the catastrophic drug coverage (CDC) ranges from $\$ 6.6$ billion to $\$ 10.3$ billion. (The CDC costs estimated under each of the CDC options include both current and new public dollars - paid by federal and provincial drug plans - that would potentially be needed to reimburse costs above a given CDC threshold.)

TABLE 1. A summary of proposals on national catastrophic drug insurance

\begin{tabular}{|c|c|c|c|c|}
\hline & $\begin{array}{l}\text { Population } \\
\text { covered }\end{array}$ & Program threshold & Payers & Payer's share \\
\hline $\begin{array}{l}\text { Kirby } \\
\text { proposal }\end{array}$ & Universal & $\begin{array}{l}\text { - } 3 \% \text { household } \\
\text { income for all } \\
\text { individuals } \\
\text { - } 3 \% \text { household } \\
\text { income or } \$ 1,500 \\
\text { for individuals with } \\
\text { private drug plans }\end{array}$ & $\begin{array}{l}\text { - } \text { Federal } \\
\text { government } \\
\text { - Provincial public } \\
\text { drug plans } \\
\text { - Private drug plans }\end{array}$ & $\begin{array}{l}\text { - Federal government: } 90 \% \text { of the cost } \\
\text { exceeding } \$ 5,000 \\
\text { - Provincial drug plans: } 10 \% \text { of the cost } \\
\text { exceeding } \$ 5,000 \text {, and } 100 \% \text { of the } \\
\text { cost between } 3 \% \text { income and } \$ 5,000 \\
\text { - Private drug plans: } 10 \% \text { of the cost } \\
\text { exceeding } \$ 5,000 \text {, and } 100 \% \text { of the } \\
\text { cost between } \$ 1,500 \text { and } \$ 5,000\end{array}$ \\
\hline $\begin{array}{l}\text { Romanow } \\
\text { proposal }\end{array}$ & $\begin{array}{l}\text { Members of } \\
\text { provincial } \\
\text { public } \\
\text { drug plans }\end{array}$ & - $\$ 1,500$ & $\begin{array}{l}\text { - Federal } \\
\text { government } \\
\text { - Provincial public } \\
\text { drug plans }\end{array}$ & $\begin{array}{l}\text { - Federal government: } 50 \% \text { of the cost } \\
\text { exceeding } \$ 1,500 \\
\text { - Provincial drug plans: } 50 \% \text { of the cost } \\
\text { exceeding } \$ 1,500\end{array}$ \\
\hline $\begin{array}{l}\text { NPS } \\
\text { proposal }\end{array}$ & Universal & $\begin{array}{l}\text { - Option I - Variable } \\
\text { percentage: } \\
\text { 0/3/6/9\% of family } \\
\text { income } \\
\text { - Option } 2 \text { - Fixed } \\
\text { percentage: } 4.3 \% \\
\text { of family income }\end{array}$ & - Not specified & - Not specified \\
\hline
\end{tabular}

However, none of these reports considers the long-run costs of these programs. Cost is a crucial determinant of long-run sustainability for such a program, and the costs of these proposed programs will not remain fixed in the long run. Prescription drug expenditure has increased rapidly in the past few decades, and this trend may continue in the future. Rising drug expenditure generates great financial pressure on provincial drug plans, private drug plans and individuals. Under a national catastrophic drug insurance plan, a certain amount of this financial pressure would be transferred to the federal 
government, and there would be a reallocation of financial responsibility for prescription drugs among provincial drug plans, private drug plans and individuals. The different design of each plan would generate different future paths for program expenditures.

The purpose of this study is to project the long-run costs to the federal government under the Kirby- and Romanow-style programs. Because of lack of information on current provincial and private drug coverage, we cannot project other public and private costs under the two proposed programs. This lack of information may be the reason why the Kirby and Romanow reports provide only cost estimates for the federal government under the proposed programs. However, the present study will still offer useful information for the shaping of a national catastrophic drug insurance plan. First, the costs to the federal government over time under the proposed programs will be crucial to their long-run sustainability. Secondly, this study explores the cost implications of different features of program design, including the eligibility threshold for federal cost-sharing and the cost-sharing rate. As shown in Table 1, the Kirby program and the Romanow program make different choices about the key parameters of program design - catastrophic threshold and federal cost-sharing rate. While the Kirby program chooses a high threshold and a high rate of cost-sharing, the Romanow program chooses a low threshold and a low rate of cost-sharing. These different approaches have different cost-sharing implications for the involved parties: the federal government, the provincial/territorial drug plans, private drug plans and individuals. The National Pharmaceuticals Strategy Progress Report (Health Canada 2006) emphasizes that the next stage of the NPS will focus on plan design, sustainability considerations and the role of engaged stakeholders. The results of this study may provide useful information on these aspects.

\section{Method}

The Fraser Group and Tristat Resources have estimated the first-year annual cost to the federal government for the Kirby-style program to be $\$ 500$ million (based on 2000). This estimate is based on the Fraser Group's proprietary database of private sector drug plans, the Survey of Labour and Income Dynamics (SLID) and the Survey of Work Arrangements (SWA).

The Romanow Commission asked the Manitoba Centre for Health Policy (MCHP) to provide a detailed analysis of drug costs for the province of Manitoba in recent years. The MCHP (2002) analysis is based on the Manitoba database maintained by the Health Information Service (Manitoba Health). The Romanow Commission then extrapolated the Manitoba data to the rest of Canada based on a number of assumptions. Details on the extrapolation are not disclosed. According to the extrapolation, the estimated annual cost to the federal government of the National 
Catastrophic Drug Transfer could range from $\$ 749.1$ million to $\$ 1.01$ billion at the base year, 2000/01.

Without access to the Fraser Group's proprietary database and details on the extrapolation by the Romanow Commission, we are unable to project the program costs based on micro-data. However, we can calculate the projections with aggregate data, using assumptions regarding the underlying distribution property of prescription drug expenditure and a Monte Carlo simulation.

The projection methods for the Kirby- and Romanow-style programs are very similar. In the year 2000, the cost of a particular program to the federal government could be written in the following way:

$$
C_{2000}=\Sigma \mathrm{i}\left(c_{i}-\text { threshold }\right)^{*} p
$$

where $\mathrm{C}_{2000}$ is the annual program cost in $2000 ; c_{\mathrm{i}}$ is the annual prescription drug expenditure of an individual who is eligible for the program and had prescription drug costs more than the program threshold in 2000; $p$ is the percentage that the federal government would pay if an individual's prescription drug expenditure exceeded the threshold. Equation (1) could be rewritten as follows:

$$
C_{2000}=p^{*}\left[N_{2000}^{*}\left(\left(\bar{c}_{2000} \mid c>\text { threshold }\right)-\text { threshold }\right)\right]
$$

In equation (2), $\mathrm{N}_{2000}$ is the number of individuals who are eligible for that program and had prescription drug costs greater than the program threshold in 2000; $\bar{c}_{2000} \mid c>$ threshold is the average prescription drug expenditure of that group of people. In a given year in the future, the annual program cost could be written as

$$
C_{t}=p^{*}\left[N_{t}^{*}\left(\left(\bar{c}_{t} \mid c>\text { threshold }\right)-\text { threshold }\right)\right]
$$

To predict the annual program cost for a program in year $t$, we need to predict $N_{t}$ and $\bar{c}_{\mathrm{t}} \mid c>$ threshold for that program.

\section{Assumptions for the projection}

Assumption 1: The individual prescription drug expenditure conditional on positive use has a log-normal distribution.

Usually the distribution of drug expenditure is right skewed with a long tail. Many individuals have low drug expenditure; a few have relatively high drug expenditure. Many studies (e.g., Duan 1983; Duggan 2005; Leibowitz et al. 1985; Manning et al. 1987; Street et al. 1999) show that the medical expenditure data are log-normally dis- 
tributed conditional on positive use. The logarithm function tends to squeeze together the larger values and stretches out the smaller values.

Assumption 2: The proportion of Canadians who have positive drug use in year 2000 is $68 \%$, and it increases at $1 \%$ per five years so that the proportion ends up at $75 \%$ of the population at the end of the projection.

In year 2000,68\% of Manitobans had taken at least one prescription drug (MCHP 2002). Since data for Canada as a whole are not available, we assume the same percentage as in Manitoba. In recent years, many new medications have been introduced, many for conditions that previously had no drug therapy. Moreover, in the next few decades Canada's population will experience a higher proportion of senior citizens as the baby boom generation ages. The aging of this demographic cohort may increase drug consumption (Morgan 2005). Assumption 2 reflects these trends.

Assumption 3: The mean of individual annual prescription drug expenditure in Canada increases at the average historical rate based on the trend in the past two decades.

The average annual growth rate of per capita prescription drug expenditure from 1985 to 2004 was 8.5\%, deflated by the Consumer Price Index (CPI) (CIHI 2005a). In the literature of cost projection, it is normal to use history as the middle level and do sensitivity checks with a value above and a value below. Therefore, we will also include two other scenarios whereby the mean prescription drug expenditure in Canada increases at $9.5 \%$ and at $6.5 \%$ annually. Health expenditures have increased dramatically in recent years worldwide. If they continue to grow at the historical rate, the healthcare system will be difficult to sustain in the near future. Therefore, cost containment will be a likely priority for governments in the next few decades (OECD 2006). The assumption of a $6.5 \%$ growth rate tries to capture the effect of future cost containment. Several developed countries (e.g., France, Germany and Switzerland) have successfully kept this rate below $6.5 \%$ in the past few decades (CIHI 2005a, 2007).

Assumption 4: In 2000, we denote the variable on the log of individual prescription drug expenditure as $z$. The mean of the underlying log-normal distribution is $\mu$ and the variance is $\sigma^{2}$, which is $z \sim\left[\mu, \sigma^{2}\right]$. In a given year in the future, we denote the variable on the log of individual prescription drug expenditure as $z$. We assume that $z^{\prime}$ is distributed as $k^{*} z$. This is an assumption about the shape of the distribution over time. We assume that the distribution in the future is proportional to the distribution in 2000. The mean of the underlying log-normal distribution will be $\mathrm{k}^{*} \mu$ and the variance will be $\mathrm{k}^{2 *} \sigma^{2}$, which is $z^{*} \sim\left[\mathrm{k} \mu, \mathrm{k}^{2} \sigma\right]$. Assumption 4 can be supported by a case study using Ontario Drug Benefit (ODB) data, which is presented in Appendix 1. 


\section{Projection of $N_{t}$}

In this step, we first project the proportion of Canadians whose prescription drug expenditure exceeds the program threshold in a given year. Secondly, we determine the number of Canadians who are eligible for the proposed program in a given year.

The basic idea of the first substep is as follows (details of the calculation are reported in Appendix 2): We assume that the prescription drug expenditure is lognormally distributed conditional on positive drug use (Assumption 1), and we know the mean of the log-normal distribution in 2000. We also know the proportion of Canadians whose prescription drug expenditure exceeds the program threshold in 2000. With the latter condition, we can estimate the variance of the underlying distribution, i.e., determine the variance. In a given year in the future, we assume that the prescription drug expenditure is still log-normally distributed. Using Assumption 3, we know the mean of the underlying distribution. And using Assumption 4, we can find out the variance of the distribution in that year. Based on these conditions, we can determine the proportion of Canadians (conditional on positive use) whose prescription drug expenditure exceeds the program threshold in that year.

This substep is slightly different for the Romanow-style program than for the Kirby-style program. Under the Romanow program, the federal government pays $50 \%$ of the costs of provincial/territorial drug insurance plans above a threshold of $\$ 1,500$ per person per year; the provincial governments are then expected to expand access to prescription drugs within their own drug insurance plans by reducing their deductibles or co-payments, or by extending coverage to people who are not now included under their plans. Using this method, we can predict the number of Canadians whose prescription drug expenditure is more than $\$ 1,500$ in a given year. However, unlike under the Kirby program, not all Canadians are going to receive subsidies from the federal government. Only those people covered by provincial/territorial drug insurance plans will receive subsidies. In a given year, we cannot explicitly predict the number of Canadians whose prescription drug expenditure will be more than $\$ 1,500$ and who are also covered by a provincial/territorial drug insurance plan. In 2000, 53\% of Canadians were covered by public drug plans (Fraser Group/Tristat Resources 2002). However, the majority of beneficiaries of provincial/territorial drug insurance plans are seniors and people with low incomes, who tend to have higher drug consumption. For example, while the Manitoba Pharmacare Program covered 57.9\% of Manitoba's population in the year 2000/01, it covered $75.7 \%$ of Manitobans whose prescription drug expenditure exceeded $\$ 1,500$ (MCHP 2002). After implementation of the Romanowstyle program, we should expect that an even higher percentage of Canadians with $\$ 1,500+$ prescription drug expenditure will be covered by provincial/territorial drug insurance plans. Therefore, for the Romanow program, we project a lower bound program cost by assuming that $75 \%$ of Canadians with $\$ 1,500+$ prescription drug expenditure are covered by provincial/territorial drug insurance plans; we project an 
upper bound program cost by assuming that $100 \%$ of Canadians with $\$ 1,500+$ prescription drug expenditure are covered by provincial/territorial drug insurance plans.

Statistics Canada (2005) projects the total Canadian population in a given year for the next 50 years. Using this population projection, we can determine the number of individuals in a given year who have prescription drug expenditures higher than the program threshold. This number is the product of the population, the proportion of the population with positive prescription drug use and the proportion of Canadians with positive prescription drug use whose prescription drug expenditure exceeds the program threshold.

Projection of mean expenditure above threshold ( ${ }^{\prime} \bar{c}_{\mathrm{t}} \mid c>$ threshold)

The mean prescription drug expenditure of the group of people whose prescription drug cost exceeds the program threshold ('ct $\mid c>$ threshold) in a given year can be found from the following integral:

$$
\left[\int_{\text {threshold }}^{+\infty} c f(c) d c\right] /\left[\int_{\text {threshold }}^{+\infty} c f(c) d c\right]
$$

where $f(c)$ is the probability density function of the log-normal distribution. It is difficult to solve this integral analytically. One common practice is to estimate this mean by a Monte Carlo simulation. After knowing the mean $(\mathrm{k} \mu)$ and standard deviation $(\mathrm{k} \sigma)$ of the prescription drug expenditure in that year, we can use a log-normal random number generator to generate a large number of observations, and then calculate the mean of those values that are higher than the program threshold.

After we have $\bar{c}_{t} \mid c>$ threshold and $N_{\mathrm{r}}$, we can calculate the total program cost in that year by equation (3). To gain a better understanding of the federal government's role in total prescription drug expenditure in Canada, we will calculate the program cost to the federal government as a proportion of total prescription drug expenditure in Canada. The total prescription drug expenditure in a given year is the product of the per capita prescription drug expenditure and the population in that year. The program threshold is unlikely to stay at the same level over time. The definition of catastrophic drug expenditure is subjective. In 2000, the threshold of the Kirby program $(\$ 5,000)$ is $7.7 \%$, and the threshold of the Romanow program $(\$ 1,500)$ is $2.3 \%$ of the average Canadian family total income (data source: CANSIM II, Table 2020701 and Table 3260002). We therefore include a scenario that assumes the threshold/income ratios are maintained at these levels over time. The annual rate of increase in average total family income is assumed at the historical level from 1985 to $2004: 3.8 \%$.

The data used to calibrate our model are drawn from CIHI (2005a,b), Statistics Canada (2005), MCHP (2002) and Kirby (2002). Detailed information on the data used, their sources and description are presented in Table 2. 
TABLE 2. Data used to calibrate the forecasting model

\begin{tabular}{|c|c|c|c|}
\hline Variable & Value & $\begin{array}{l}\text { Data (reference) } \\
\text { source }\end{array}$ & Description \\
\hline $\begin{array}{l}\text { Per capita prescription } \\
\text { drug expenditure in } \\
\text { Canada, } 2000\end{array}$ & $\$ 383.5$ & $\begin{array}{l}\text { ClHI 2005b, data table } \\
\text { A. } 3\end{array}$ & $\begin{array}{l}\text { This estimate is based on } \\
\text { information collected by } \\
\mathrm{CIHI} \text { from various federal } \\
\text { government agencies, } \\
\text { provincial and municipal } \\
\text { governments, private } \\
\text { insurers and survey data. }\end{array}$ \\
\hline $\begin{array}{l}\text { Canadian population, } \\
\text { 2000-2035 }\end{array}$ & - & Statistics Canada 2005 & $\begin{array}{l}\text { The latest publication of } \\
\text { population projections by } \\
\text { Statistics Canada. }\end{array}$ \\
\hline $\begin{array}{l}\text { Percentage of Canadians } \\
\text { who had positive } \\
\text { prescription drug use } \\
\text { in } 2000\end{array}$ & $68 \%$ & MCHP 2002 & $\begin{array}{l}\text { In year } 2000,68 \% \text { of } \\
\text { Manitobans had taken } \\
\text { at least one prescription } \\
\text { drug. Original data source } \\
\text { for this estimate is Health } \\
\text { Information Services } \\
\text { (Manitoba Health). } \\
\text { Since the corresponding } \\
\text { Canadian data are not } \\
\text { available, we assume the } \\
\text { same percentage as in } \\
\text { Manitoba. }\end{array}$ \\
\hline $\begin{array}{l}\text { Total cost of the Kirby-style } \\
\text { program in } 2000\end{array}$ & $\$ 500$ million & Kirby 2002 & $\begin{array}{l}\text { This estimate is provided } \\
\text { by Fraser Group and } \\
\text { Tristat Resources at the } \\
\text { request of the Kirby } \\
\text { Committee. It is based } \\
\text { on the Fraser Group's } \\
\text { proprietary database of } \\
\text { private sector drug plans, } \\
\text { the Survey of Labour } \\
\text { Income Dynamics (SLID) } \\
\text { and the Survey of Work } \\
\text { Arrangement (SWA). }\end{array}$ \\
\hline $\begin{array}{l}\text { Number of Canadians } \\
\text { with } \$ 5,000+\text { prescription } \\
\text { drug expenditure in } 2000\end{array}$ & 100,000 & Kirby 2002 & $\begin{array}{l}\text { This estimate is provided } \\
\text { by the Fraser Group and } \\
\text { Tristat Resources based on } \\
\text { the information mentioned } \\
\text { above. }\end{array}$ \\
\hline $\begin{array}{l}\text { Average annual increase } \\
\text { in rate of per capita } \\
\text { prescription drug } \\
\text { expenditure in Canada, } \\
\text { 1985-2004 }\end{array}$ & $8.5 \%$ & $\mathrm{CIHI} 2005 \mathrm{a}$ & $\begin{array}{l}\text { This estimate is based on } \\
\text { information collected by } \\
\mathrm{CIHI} \text { from various federal } \\
\text { government agencies, } \\
\text { provincial and municipal } \\
\text { governments, private } \\
\text { insurers and survey data. }\end{array}$ \\
\hline
\end{tabular}


Program Design and Long-Run Costs of a National Catastrophic Drug Insurance Plan

\section{Results}

The program costs to the federal government as a proportion of total prescription drug expenditure in Canada are presented in Tables 3 and 4. The annual program costs of both the Kirby- and the Romanow-style programs will increase dramatically, even if the program threshold is raised over time. One fundamental reality is that prescription drug expenditure has increased rapidly in the past few decades, and this trend may continue in the future.

TABLE 3. Annual program costs to the federal government, constant threshold, as a proportion of total prescription drug expenditure in Canada, low-, middle- and high-growth scenarios

\begin{tabular}{|c|c|c|c|c|c|c|c|c|c|}
\hline & \multicolumn{6}{|c|}{ Romanow-style program } & \multicolumn{3}{|c|}{ Kirby-style program } \\
\hline & \multicolumn{6}{|c|}{$\begin{array}{l}\text { Assumed rate of increase in annual mean prescription drug } \\
\text { expenditure }\end{array}$} & \multirow{2}{*}{\multicolumn{3}{|c|}{$\begin{array}{l}\text { Assumed rate of increase in } \\
\text { annual mean prescription drug } \\
\text { expenditure }\end{array}$}} \\
\hline & \multicolumn{2}{|c|}{$6.5 \%$} & \multicolumn{2}{|c|}{$8.5 \%$} & \multicolumn{2}{|c|}{$9.5 \%$} & & & \\
\hline Time & $\begin{array}{l}\text { Lower } \\
\text { bound }\end{array}$ & $\begin{array}{l}\text { Upper } \\
\text { bound }\end{array}$ & $\begin{array}{l}\text { Lower } \\
\text { bound }\end{array}$ & $\begin{array}{l}\text { Upper } \\
\text { bound }\end{array}$ & $\begin{array}{l}\text { Lower } \\
\text { bound }\end{array}$ & $\begin{array}{l}\text { Upper } \\
\text { bound }\end{array}$ & $6.5 \%$ & $8.5 \%$ & $9.5 \%$ \\
\hline 2000 & $5.7 \%$ & $7.6 \%$ & $5.7 \%$ & $7.6 \%$ & $5.7 \%$ & $7.6 \%$ & $4.3 \%$ & $4.3 \%$ & $4.3 \%$ \\
\hline 2005 & $8.8 \%$ & $11.8 \%$ & $9.9 \%$ & $13.2 \%$ & $10.4 \%$ & $13.9 \%$ & $4.1 \%$ & $5.1 \%$ & $5.7 \%$ \\
\hline 2010 & $12.4 \%$ & $16.5 \%$ & |4.7\% & $19.6 \%$ & $15.8 \%$ & $21.1 \%$ & $7.9 \%$ & $11.1 \%$ & $12.9 \%$ \\
\hline 2015 & I5.9\% & $21.2 \%$ & $19.2 \%$ & $25.6 \%$ & $20.9 \%$ & $27.8 \%$ & $13.2 \%$ & $19.3 \%$ & $22.8 \%$ \\
\hline 2020 & $19.3 \%$ & $25.8 \%$ & $23.3 \%$ & $31.1 \%$ & $25.0 \%$ & $33.3 \%$ & $19.9 \%$ & $29.5 \%$ & $34.5 \%$ \\
\hline 2025 & $22.4 \%$ & $29.9 \%$ & $26.6 \%$ & $35.5 \%$ & $28.3 \%$ & $37.7 \%$ & $27.8 \%$ & $40.3 \%$ & $46.4 \%$ \\
\hline 2030 & $25.2 \%$ & $33.7 \%$ & $29.2 \%$ & $39.0 \%$ & $30.7 \%$ & $41.0 \%$ & $35.9 \%$ & $50.5 \%$ & $57.1 \%$ \\
\hline 2035 & $27.5 \%$ & $36.7 \%$ & $31.3 \%$ & $41.7 \%$ & $32.4 \%$ & $43.3 \%$ & $44.1 \%$ & $59.8 \%$ & $65.6 \%$ \\
\hline
\end{tabular}

Notes: I) We include a high- and a low-growth scenario for both programs whereby the annual mean prescription drug expenditure in Canada increases at $9.5 \%$ and at $6.5 \%$, respectively.

2) For the Romanow-style program, we project a lower-bound program cost by assuming that $75 \%$ of Canadians with $\$ 1,500+$ prescription drug expenditure are covered by provincial/territorial drug insurance plans; we project an upper-bound program cost by assuming that I00\% of Canadians with $\$ 1,500+$ prescription drug expenditure are covered by provincial/territorial drug insurance plans.

3) For the Kirby-style program, we assume that all Canadians are covered by the proposed program.

Under both the Romanow- and the Kirby-style programs, the federal government would pick up a share of prescription drug expenditure in the future. Moreover, as Grootendorst and Veall (2005) point out, the federal government will share the open-ended upper tail of the distribution. Therefore, the allotment of prescription drug costs among the federal government, provincial governments, private drug plans and individuals will be altered significantly in the future, and a large proportion of the financial responsibility for prescription drugs will be transferred to the federal government. In 2004, the amount paid by the federal government on total prescription 
drug expenditure was $2.7 \%$ (CIHI 2005a). If per capita prescription drug expenditure increases at the historical rate of the past two decades, the federal government's share of total prescription drug expenditure under either of the two programs will increase rapidly over time. To avoid this situation, the federal government would have to raise the program threshold more rapidly than the growth of average family income, a policy that may conflict with the purpose of these programs - providing Canadians protection from catastrophic drug costs.

TABLE 4. Annual program costs to the federal government, increased program threshold, as a proportion of total prescription drug expenditure in Canada, low-, middle- and high-growth scenarios

\begin{tabular}{|c|c|c|c|c|c|c|c|c|c|}
\hline & \multicolumn{6}{|c|}{ Romanow-style program } & \multicolumn{3}{|c|}{ Kirby-style program } \\
\hline & \multicolumn{6}{|c|}{$\begin{array}{l}\text { Assumed rate of increase in annual mean prescription drug } \\
\text { expenditure }\end{array}$} & \multirow{2}{*}{\multicolumn{3}{|c|}{$\begin{array}{l}\text { Assumed rate of increase in annual } \\
\text { mean prescription drug expenditure }\end{array}$}} \\
\hline & \multicolumn{2}{|c|}{$6.5 \%$} & \multicolumn{2}{|c|}{$8.5 \%$} & \multicolumn{2}{|c|}{$9.5 \%$} & & & \\
\hline Time & $\begin{array}{l}\text { Lower } \\
\text { bound }\end{array}$ & $\begin{array}{l}\text { Upper } \\
\text { bound }\end{array}$ & $\begin{array}{l}\text { Lower } \\
\text { bound }\end{array}$ & $\begin{array}{l}\text { Upper } \\
\text { bound }\end{array}$ & $\begin{array}{l}\text { Lower } \\
\text { bound }\end{array}$ & $\begin{array}{l}\text { Upper } \\
\text { bound }\end{array}$ & $6.5 \%$ & $8.5 \%$ & $9.5 \%$ \\
\hline 2000 & $5.7 \%$ & $7.6 \%$ & $5.7 \%$ & $7.6 \%$ & $5.7 \%$ & $7.6 \%$ & $4.3 \%$ & $4.3 \%$ & $4.3 \%$ \\
\hline 2005 & $7.2 \%$ & $9.6 \%$ & $8.2 \%$ & $10.9 \%$ & $8.7 \%$ & $11.6 \%$ & $3.0 \%$ & $3.7 \%$ & $4.1 \%$ \\
\hline 2010 & $8.8 \%$ & $11.8 \%$ & $10.9 \%$ & $14.5 \%$ & $12.1 \%$ & $16.1 \%$ & $4.4 \%$ & $6.6 \%$ & $7.9 \%$ \\
\hline 2015 & $10.4 \%$ & $13.9 \%$ & $13.6 \%$ & $18.1 \%$ & $15.2 \%$ & $20.3 \%$ & $6.2 \%$ & $10.4 \%$ & $12.9 \%$ \\
\hline 2020 & $11.9 \%$ & 15.9\% & $16.2 \%$ & $21.7 \%$ & $18.3 \%$ & $24.4 \%$ & $8.5 \%$ & $15.0 \%$ & $19.0 \%$ \\
\hline 2025 & $13.6 \%$ & $18.2 \%$ & $18.8 \%$ & $25.0 \%$ & $21.2 \%$ & $28.2 \%$ & $11.2 \%$ & $20.6 \%$ & $26.0 \%$ \\
\hline 2030 & $15.2 \%$ & $20.3 \%$ & $21.1 \%$ & $28.1 \%$ & $23.7 \%$ & $31.6 \%$ & $14.0 \%$ & $26.6 \%$ & $33.3 \%$ \\
\hline 2035 & $16.7 \%$ & $22.3 \%$ & $23.2 \%$ & $31.0 \%$ & $25.9 \%$ & $34.5 \%$ & $17.3 \%$ & $32.6 \%$ & $40.5 \%$ \\
\hline
\end{tabular}

Note: Please refer to the notes for Table 3.

The first-year costs of the Kirby-style program to the federal government are lower than those of the Romanow-style program. However, the annual program cost of the Kirby program will exceed the annual cost of the Romanow program in the long run. Figures 1 and 2 show the total annual program costs, over time, as a proportion of total prescription drug expenditure in Canada. Figure 1 uses the fixed program threshold and Figure 2 uses the more realistic assumption of increased thresholds. Although the Kirby-style program requires less initial expenditure by the federal government than does the Romanow-style program, over time the Kirby program becomes more expensive. Under the Kirby program, the federal government pays $90 \%$ of an individual's prescription drug cost over $\$ 5,000$. Under the Romanow program, the federal government pays $50 \%$ of an individual's prescription drug cost over $\$ 1,500$. 
When per capita prescription drug cost is low, a high threshold leads to a lower total program cost. As per capita prescription drug cost increases over time at a rate faster than the growth in household income, the proportion of Canadians whose drug costs exceed the threshold becomes greater and thus the rate of sharing plays a more important role in the total cost of the program.

FIGURE 1. Annual total program costs to the federal government as a proportion of total prescription drug expenditure in Canada, fixed program threshold, 2000-2035

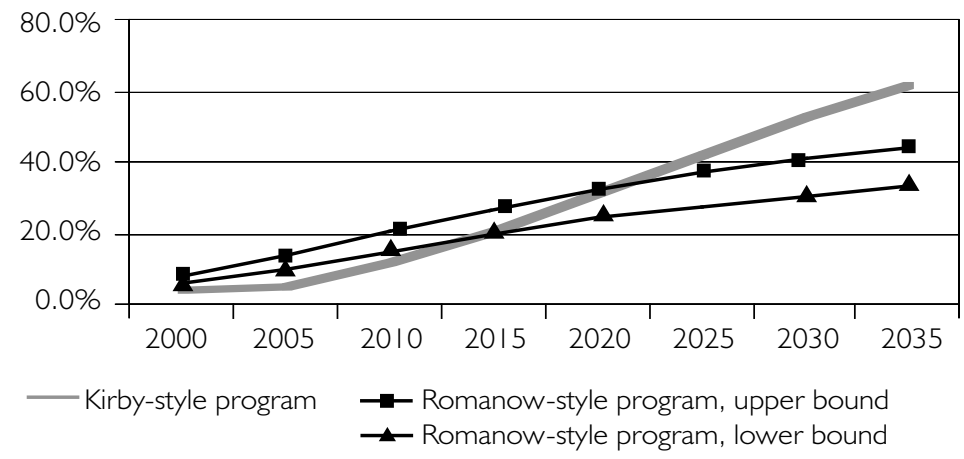

Note: An $8.5 \%$ annual rate of increase in average prescription drug expenditure in Canada is assumed.

FIGURE 2. Per capita program costs to the federal government, Kirby and Romanow programs, with increased program threshold, 2000-2035

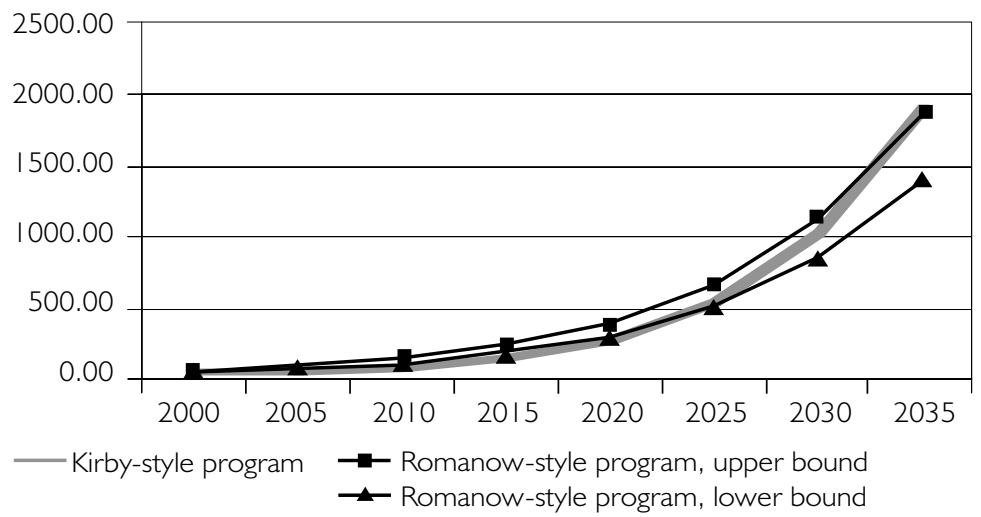

Note: An $8.5 \%$ annual rate of increase in average prescription drug expenditure in Canada is assumed.

For the same reason, the Kirby program is more sensitive to the growth rate of mean prescription drug expenditure in Canada. If the mean prescription drug expenditure increases at the average historical rate of the past two decades $(8.5 \%)$ (CIHI 2005a), and the program threshold maintains its initial threshold/income ratio, in 2035 the federal share of total prescription drug expenditure in Canada under the Kirby-style program will be $32.6 \%$. However, if the mean prescription drug expenditure increases at $6.5 \%$, the federal share of the total prescription drug expenditure is 
$17.3 \%$. The gap between these two scenarios is $15.3 \%$, but for the Romanow-style program, this gap is only $8.7 \%$. This pattern can be observed in Figure 3.

FIGURE 3. Program costs as a proportion of total prescription drug expenditure in Canada, different growth rates of mean prescription drug expenditure, 2000-2035

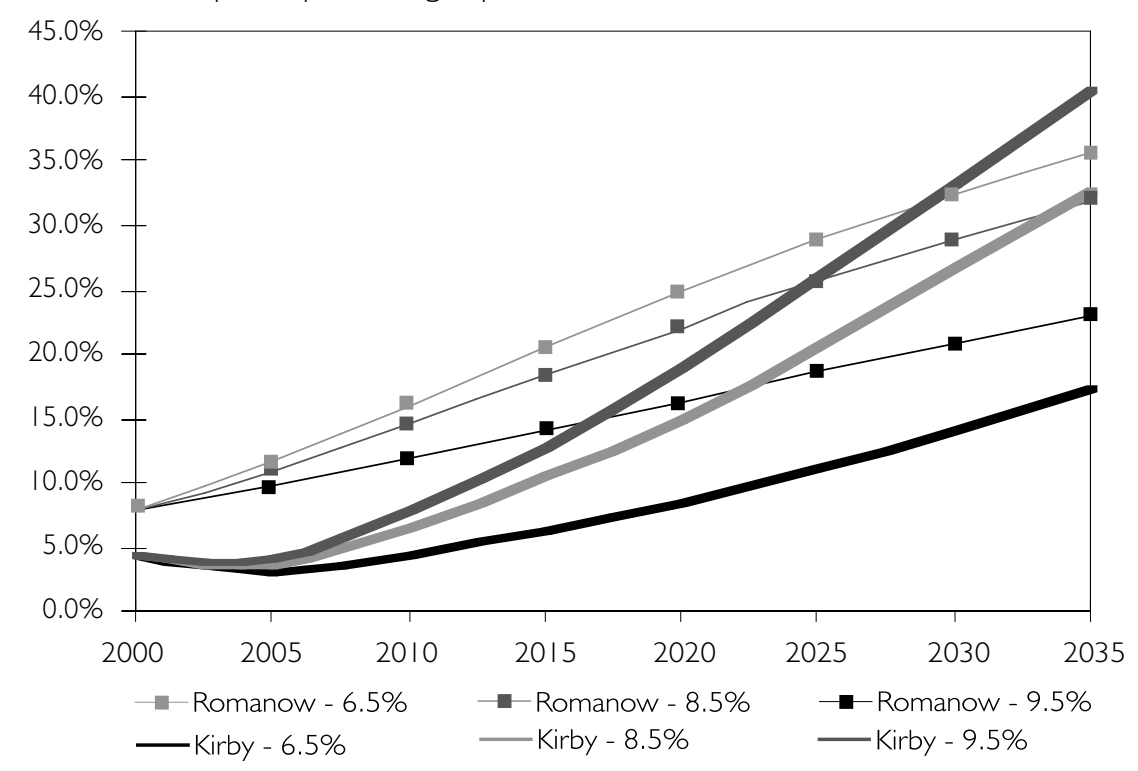

Note: Only the upper-bound costs of the Romanow-style program are presented in the above figure.

\section{Limitations and Conclusion}

In the long run, many factors may increase the costs of the proposed programs, including population growth, population aging, increasing utilization of pharmaceuticals, drug prices, incomes, behavioural responses from provincial drug plans, private drug plans and individuals (CIHI 2005a). By assuming that per capita prescription drug expenditure will grow at the average historical rate in the future, we implicitly assume that the past trends of population growth, population aging, increased pharmaceutical utilization, increased drug prices and higher incomes will also continue in the future. Assumption 2 incorporates acceleration of population aging in the cost projections.

However, the above analysis has several limitations. First, this analysis does not take into account possible behavioural responses from provincial or private drug plans and individuals. The provincial drug plans may have incentives to shift the financial burden to the federal programs, and the individuals who benefit may increase their drug utilization. The Kirby-style program may suffer more moral hazard problems from provincial/private drug plans in the long run because of the high federal costsharing rate. Furthermore, the new federal program may generate a crowding-out effect on private drug insurance. All these factors will increase the total cost of the 
proposed program to the federal government. Secondly, in the future, population aging, introduction of costly new drugs, and the higher proportion of the population who need to spend extraordinarily large amounts on drugs may increase the skewness of the distribution. Therefore, the simulation may underestimate program costs because of the rightward skewness, especially in the early years of the cost projections. This underestimation is more serious when we assume that the program threshold is raised over time, because the group of beneficiaries is smaller compared to the case when the program threshold is fixed. Therefore, the cost projections in this analysis should be considered only as lower-bound estimates.

From the above analysis, we know that both the annual program cost and the federal government's share of total prescription drug expenditures will increase dramatically under both the Kirby-and the Romanow-style programs. Although the Kirby program requires less expenditure by the federal government than does the Romanow program in the first year, over time the Kirby program actually becomes more expensive. The underlying reason is that while the federal government will share the openended upper tail of the distribution under both programs, the Romanow program effectively downloads more of the prescription drug costs to other payers. A larger proportion of the increase in prescription drug expenditure would be transferred from provincial or private drug plans to the federal government under the Kirby program. For the same reason, the Kirby program is more sensitive to the growth rate of mean prescription drug expenditure.

In designing a national catastrophic drug insurance plan, one fundamental reality that cannot be ignored is the rapid increase in prescription drug expenditure. This rapid increase will have a far-reaching influence on long-run program costs. The cost implications to the federal government of the program threshold and federal cost-sharing rate will change over time. As the per capita prescription drug cost increases, the sharing rate, rather than the program threshold, will play a more important role in total program costs to the federal government.

Although a national catastrophic drug insurance plan will incur great public expenditure, the total costs to the healthcare system as a whole may not increase so much. Soumerai et al. $(1991,1994)$ show that restrictions on drug use in the US Medicaid program have led to cost increases for other healthcare services. In the Canadian context, Tamblyn et al. (2001) show that the imposition in Quebec of costsharing for drugs decreased the use of essential drugs among the elderly and among welfare recipients, resulting in significant increases in hospitalizations, nursing home admissions, deaths and emergency department visits. Although these authors do not present cost data, the increase in serious adverse events seems likely to have raised total costs. Under a national catastrophic drug insurance plan, improved morbidity and mortality in the population may reduce the costs elsewhere in the healthcare system. One useful direction for future research may therefore be to explore the link 
between prescription drug expenditure and other healthcare expenditures.

Options for a national catastrophic drug insurance plan represent different ways of realigning prescription drug expenditures in Canada among the federal government, provincial and private plans, and individual payers. The above analysis shows that if a single payer assumes most of the financial responsibility, it will face escalated pressure over time, possibly threatening the program's sustainability. Moreover, the program threshold and cost-sharing rates are crucial to the future costs incurred by the payers. In conclusion, in order to maintain long-term program sustainability, future analyses should pay close attention to plan design and the role of engaged stakeholders.

Correspondence may be directed to: Hai Zhong, School of Public Finance and Public Policy, Central University of Finance and Economics, 39 South College Road, Beijing, China 100081; tel.: 86-10-62288775; fax: 86-10-62288535; e-mail: haizhong@cufe.edu.cn.

\section{ACKNOWLEDGEMENTS}

This paper is part of my doctoral dissertation at McMaster University. I would like to thank my supervisor Jerry Hurley, Tom Crossley and John Leach, all of McMaster University, for their helpful comments and invaluable guidance. I would also like to thank Lonnie Magee and Mike Veall for their help on statistics. I am solely responsible for any remaining errors and omissions.

\section{REFERENCES}

Canadian Institute for Health Information (CIHI). 2005a. Drug Expenditure in Canada, 1985 to 2004. Ottawa: Author.

Canadian Institute for Health Information (CIHI). 2005b. National Health Expenditure Trends, 1975 to 2004. Ottawa: Author.

Canadian Institute for Health Information (CIHI). 2007. Drug Expenditure in Canada, 1985 to 2006. Ottawa: Author.

Duan, N. 1983. "Smearing Estimate: A Non-Parametric Retransformation Method." Journal of the American Statistical Association 78: 605-10.

Duggan, M.G. 2005. "Do New Prescription Drugs Pay for Themselves? The Case of SecondGeneration Antipsychotics." Journal of Health Economics 24: 1-31.

Fraser Group/Tristat Resources. 2002. Drug Expense Coverage in the Canadian Population: Protection from Severe Drug Expenses. Ottawa: Canadian Life and Health Insurance Association. Retrieved May 16, 2008. <http://www.frasergroup.com/downloads/severe_drug_e.pdf >.

Grootendorst, P. and M.R. Veall. 2005. "National Catastrophic Drug Insurance Revisited: Who Would Benefit from Senator Kirby's Recommendations?" Canadian Public Policy 31(4): 341-58.

Health Canada. 2006. National Pharmaceuticals Strategy Progress Report. Retrieved May 16, 2008. $<$ http://www.hc-sc.gc.ca/hcs-sss/pubs/pharma/2006-nps-snpp/index_e.html>.

Kirby, M. 2002."Expanding Coverage to Include Protection against Catastrophic Prescription Drug Costs." Chapter 7, Volume 6 of The Health of Canadians - The Federal Role. Ottawa: Standing Senate Committee on Social Affairs, Science and Technology. 
Leibowitz, A., W.G. Manning and J.P. Newhouse. 1985.“The Demand for Prescription Drugs as a Function of Cost-Sharing." Social Science and Medicine 21: 1063-169.

Manitoba Centre for Health Policy (MCHP). 2002. Unpublished data prepared for the Commission on the Future of Health Care in Canada.

Manning, W.G., J.P. Newhouse, N. Duan, E.B. Keeler, A. Leibowitz and M.S. Marquis. 1987. "Health Insurance and the Demand for Medical Care: Evidence from a Randomized Experiment." American Economic Review 77: 251-77.

Morgan, S.G. 2005. “Booming Prescription Drug Expenditure: A Population-Based Analysis of Age Dynamics." Medical Care 43(10): 996-1008.

Ontario Ministry of Health and Long-Term Care. 2001. 2000/01 Report Card for the Ontario Drug Benefit Program. Toronto: Author.

Ontario Ministry of Health and Long-Term Care. 2005. 2004/05 Report Card for the Ontario Drug Benefit Program. Toronto: Author.

Organisation for Economic Co-operation and Development (OECD). 2006. Projecting OECD Health and Long-Term Care Expenditures: What Are the Main Drivers? Economics Department Working Papers No. 477. Paris: Author.

Romanow, R.J. 2002. "Prescription Drugs." Chapter 9 of Building on Values: The Future of Health Care in Canada. Ottawa: Commission on the Future of Health Care in Canada.

Soumerai, S.B., T.J. McLaughlin, D. Ross-Degnan C.S. Castens, P. Bollini. 1994. “Effects of Limiting Medicaid Drug Reimbursement Benefits on the Use of Psychotropic Agents and Acute Mental Health Services by Patients with Schizophrenia." New England Journal of Medicine 331(10): 650-55.

Soumerai, S.B., D. Ross-Degnan, J. Avorn, T. McLaughlin, I. Choodnovskiy. 1991."Effects of Medicaid Drug-Payment Limits on Admissions to Hospitals and Nursing Homes. New England Journal of Medicine 325(15): 1072-77.

Statistics Canada. 2005. Population Projections for Canada, Provinces and Territories, 2005-2031. Ottawa: Author.

Street, A., A. Jones and A. Furuta. 1999. "Cost-Sharing and Pharmaceutical Utilisation and Expenditure in Russia." Journal of Health Economics 18: 459-72.

Tamblyn, R., R. Laprise, J.A. Hanley M. Abrahamowicz, S. Scott, N. Mayo, J. Hurley, R. Grad, E. Latimer, R. Perreault, P. McLeod, A. Huang, P. Larochelle, L. Mallet. 2001. "Adverse Events Associated with Prescription Drug Cost-Sharing among Poor and Elderly Persons." Journal of the American Medical Association 285(4): 421-29.

\section{Appendix 1: A Case Study to Support Assumptions 1 and 4}

The group means of the top 5\%,10\%,15\% and 20\% of users of the Ontario Drug Benefit (ODB) program in 2004/05 can be found in the 2004/05 Report Card for the Ontario Drug Benefit Program (Ontario Ministry of Health and Long-Term Care 2005). In this Appendix, we use the method described under Method to project those group means based on the 2000/01 ODB data. If Assumptions 1 and 4 hold true, the projected numbers for 2004/05 should be very close to the actual numbers. 
The ODB program is not a population insurance program in that it selectively targets persons with very high-cost drugs, and thus the upper 5\%,10\%, 15\% and 20\% of costs for this group would not be typical of the entire population. However, we can assume that both the expenditure distribution for the ODB beneficiaries and for the entire population are log-normal, although they have different means and variances. Our method can be applied to any log-normal distributions. We use the ODB data to verify the two assumptions, since ODB provides detailed information on cost distributions.

We find that the two sets of numbers are very close. The comparison is presented in Table A1.

The simulated numbers are slightly lower than the true value. A possible reason is that for the given mean and standard deviation, the simulation does not generate sufficient outliers. The impact of those missing outliers on the group mean in the simulation is significant when the group size is small. An alternative interpretation is that the variance of the distribution increases faster than the assumption that the standard error rises in lock-step with the mean allows. This is one limitation of this projection method, and it may lead to downward bias of the projection. As the group size becomes larger, the influence of the outliers will become less significant; therefore, the simulated group means will become closer to the true values. This pattern can be observed in Table A1. The result demonstrates that the reliability of the simulation increases as the group size increases.

TABLE A1. Simulated group means and the real group means from ODB data

\begin{tabular}{|l|l|l|l|}
\hline \multirow{2}{*}{} & \multicolumn{2}{|l|}{ Group mean } & Difference \\
\cline { 2 - 4 } & ODB data, 2004/05 & Simulation & $\$ 596$ \\
\hline Top 5\% & $\$ 8,446$ & $\$ 7,850$ & $\$ 261$ \\
\hline Top 10\% & $\$ 6,194$ & $\$ 5,933$ & $\$ 204$ \\
\hline Top 15\% & $\$ 5,162$ & $\$ 4,958$ & $\$ 164$ \\
\hline Top 20\% & $\$ 4,491$ & $\$ 4,327$ & \\
\hline
\end{tabular}

Note: The simulation is based on the method described in the Method section of the paper.

\section{Appendix 2: Technical Details of the Projection Method}

In this Appendix, we use the Kirby-style program to illustrate the method of projecting the proportion of Canadians whose prescription drug expenditure exceeds the threshold in a given year. As reported in Table 2, we have the following initial conditions in year 2000: 
$+\mathrm{C}_{2000}=\$ 500$ million.

- $\quad \mathrm{N}_{2000}=100,000$ (number of individuals with prescription drug costs over the program threshold $(\$ 5,000)$, or $0.47 \%$ of the subpopulation that have positive drug use. In other words, $99.53 \%$ of Canadians with positive drug use had prescription drug expenditures of less than $\$ 5,000$ in 2000 .

- Therefore, from equation (2), we arrive at $\bar{c}_{2000}=\$ 10,556$.

- Mean prescription drug expenditure in Canada in 2000 is $\$ 383.35$ (CIHI 2005a).

- Sixty-eight per cent of Canadians had positive prescription drug use in 2000; therefore, the mean prescription drug expenditure for those Canadians is $\$ 563.75$.

With these initial conditions, we could estimate the mean $(\mu)$ and variance $(\sigma)$ of the log-normal distribution in 2000 by using the following two general results:

$$
\begin{aligned}
& E(\operatorname{esp}(z))=e^{\left(\mu+\sigma^{2} / 2\right)} \\
& \operatorname{prob}\left(-\infty<\frac{\ln 5000-\mu}{\sigma}<Q\right)=0.9953
\end{aligned}
$$

Equation (4) is the first moment of a log-normal distribution, where $E(\operatorname{esp}(z))$ equals $\$ 563.75$ in 2000 . Equation (5) is from standardization of the following equation:

$$
\operatorname{prob}(-\infty<z<Q)=0.9953
$$

Equations (5) and (6) mean that $99.53 \%$ of Canadians with positive drug use had prescription drug expenditures of less than $\$ 5,000$ in 2000 . From a standard normal distribution table, we can find the value of $Q$ corresponding to 0.9953 . With equations (4) and (5), we have two equations and two unknown variables, and we can then solve for $\mu$ and $\sigma$ in 2000. For the given data, we have

$$
563.75=e^{\left(\mu+\sigma^{2} / 2\right)}
$$

Taking log on both sides, we get

$$
\ln (563.75)=\mu+\sigma^{2} / 2
$$

According to equation (5) and the value of $Q$ corresponding to 0.9953 (the proportion with prescription drug expenditure less than $\$ 5,000$ ), from a standard normal distribution table, we have 


$$
\underline{\ln 5000-\mu}=2.594
$$

$\sigma$

With equations (8) and (9), we have two equations and two unknown variables, and then we can solve for $\mu$ and $\sigma$ in 2000:

$$
\mu=5.776, \sigma=1.057
$$

In a given year $t$ in the future, with Assumption 3, we have the following condition:

$$
E\left(\exp \left(z^{\prime}\right)\right)=\mathrm{e}^{\left(k \mu+k^{2} \sigma^{2} / 2\right)}
$$

From Assumption 2, we know the mean prescription drug expenditure $\mathrm{E}\left(\exp \left(z^{\prime}\right)\right)$ in that year, enabling us to estimate the only unknown variable $\mathrm{k}$ in equation (11). With this $k$, we can calculate $Q:$

$$
\frac{\ln 5000-k^{*} \mu}{\mathrm{k}^{*} \sigma}=Q
$$

From this $Q$, with a standard normal distribution table, we can calculate $x$ :

$$
\operatorname{prob}\left(0<\frac{\ln 5000-k^{*} \mu}{k^{*} \sigma}<Q\right)=x
$$

The percentage with more than $\$ 5,000$ prescription drug expenditure in that year is $1-x$. For example, in the year 2005, the mean prescription drug expenditure conditional on positive prescription drug use is $\$ 847.69$ (8.5\% annual growth rate). According to equation (11), we have

$$
847.69=e^{\left(k \mu+k^{2} \sigma^{2} / 2\right)}
$$

Taking $\log$ on both sides, we get

$$
\ln (847.69)=k \mu+\mathrm{k} 2 \sigma 2 / 2
$$

Substituting (10) into (15), we can solve for k:

$$
k=1.059
$$


Program Design and Long-Run Costs of a National Catastrophic Drug Insurance Plan

According to equation (12), with the $\mathrm{k}, \mu$ and $\sigma$ in (10) and (16), we can calculate the critical value $Q:$

$$
\underline{\ln 5000-1.059 * 5.776}=Q=2.146
$$

$1.059^{*} 1.057$

With this $Q$, from the standard normal distribution table, we can determine $\mathrm{x}$ :

$$
x=0.984
$$

Therefore, in $2005,1-x=0.016$, so $1.6 \%$ of Canadians with positive prescription drug use would have had more than $\$ 5,000$ prescription drug expenditure. Similarly, we can calculate this proportion in the other years. 